\title{
LA IGLESIA PRERROMÁNICA DE SAN MARTÍN DE PRADO EN LALÍN, PONTEVEDRA-ESPAÑA
}

\author{
(THE PRE-ROMANIC CHURCH OF SAN MARTÍN DE PRADO IN LALÍN, PONTEVEDRA-SPAIN)
}

\author{
Santiago Feijoo Martínez y Víctor Rúa Carril \\ Universidad de Santiago de Compostela \\ ESPAÑA
}

Fecha de recepción: 13 -II-95

\section{RESUMEN}

San Martín de Prado es una iglesia del S.XVI de una sola nave y pequeño tamaño, pero, enmascarados en sus muros, conserva paramentos prerrománicos y románicos de gran interés. Nosotros hemos constatado, aparte del abandono que sufren, que otras iglesias de la zona también los poseen en mayor o menor grado.

Estos elementos, aislados, prácticamente no tienen valor, pero en conjunto, ofrecen grandes posibilidades de estudio a todos los niveles: Restauración, hábitat en la Edad Media, tipologias de paramentos, etc.

El trabajo se refiere sólo a San Martín y está realizado con gran economía de medios, acordes, quizá, con el modesto objeto de estudio. Los elementos han sido estudiados en profundidad y, gracias a la sencillez de la iglesia, pensamos que pueden ser fácilmente reconocidos sin necesidad de una buena planimetria (de la que, no cabe duda, a los autores les habria encantado disponer).

\section{SUMMARY}

San Martin de Prado is a small, single-nave church from the XVI century. However, concealed in its walls, there are PreRomanic and Romanic layers of great interest. The authors of the article have reached the conclusion that, beside the abandonment they all suffer, the rest of the churches in the area must also have these characteristics, to a greater or smaller extent.

When taken separately, these elements have practically no value at all, but as a whole, they offer great possibilities of study at all levels; restoration, mediaeval habitat, types of walls.

This work refers only to San Martin and has been carried out with limited means, perhaps in accordance with the modest objective of the study. The elements have been studied in depth, and owing to the great simplicity of the church, we may be allowed to believe that they can be easily recognized without the need for a good planimetry measures, which, no doubt, would have been of great help description of the actions undertaken (their criteria and typology) and the conclusions.

\section{Introducción}

El análisis de San Martín de Prado forma parte de un trabajo más amplio que pretendía documentar todas la iglesias de la Comarca de Lalín (Pontevedra). Se planteó al constatar la nula atención que sufren las parroquias rurales por parte de las Administraciones (tanto Central como Autonómica), que las dejanal librealbedrío de las feligresías, pues en todas ellas continúa el culto, y éstas, con toda su buena fe, han procedido a hacer "restauraciones" prácticamente irreversibles. Esta situación se ha dado fundamentalmente porque no había ningún elemento de juicio que les diera algún valor histórico o. artístico: carecen de decoración antigua, son más bien pequeñitas, las hay a cientos y las que aún conservan partes medievales o altomedievales, éstas aparecen enmascaradas por las reformas posteriores. Entonces, obviamente, han sido ignoradas. Aunque, todo hay que decirlo, no tanto por un deseo consciente, como por la dificultad que ha planteado encontrar estos elementos. De quince iglesias prospectadas de un total de cuarenta y ocho, al menos cinco poseen restos prerrománicos ${ }^{1} \mathrm{o}$ románicos totalmente inéditos.

1. Debemos aclarar que cuando utilizamos el término "prerrománico" lo hacemos en el sentido etimológico de la palabra, como previo al románico, ya que por ahora es imposible precisar más. 


\begin{tabular}{|c|c|}
\hline $\begin{array}{l}\text { IGLESIAS DE } \\
\text { LA COMARCA } \\
\text { DE LALIN }\end{array}$ & 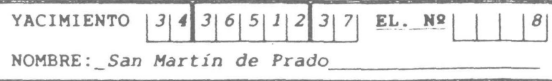 \\
\hline \multicolumn{2}{|c|}{$\begin{array}{l}\text { DESCRIPCION: Ampliación de } 0,60 \mathrm{~ms} \text { al este, formada por sillares } \\
\text { bien escuadrados y acabados, penetrando al EL. nQ2 en alter- } \\
\text { nancia de sillares para trabar bien con esta, y a su vez, es } \\
\text { penetrado por el EL. n\&16 con el mismo fin. En su parte supe- } \\
\text { rior se identifica plenamente con el EL. n\&7 por lo que tambier } \\
\text { se aprecia el cambio de color textura y forma con respecto al } \\
\text { EL. n\&2. Tiene el borde E desgastado. }\end{array}$} \\
\hline \multicolumn{2}{|r|}{ SE LE ADOSA: 16,25} \\
\hline \multicolumn{2}{|r|}{\begin{tabular}{l|l} 
& CORTADO POR: 16 \\
\end{tabular}} \\
\hline \multicolumn{2}{|c|}{\begin{tabular}{l|l} 
& SE LE APOYA:
\end{tabular}} \\
\hline \multicolumn{2}{|c|}{\begin{tabular}{l|l} 
CUBRE A : & CUBIERTO POR:
\end{tabular}} \\
\hline \multicolumn{2}{|c|}{\begin{tabular}{l|l} 
UNE A : 7 & IGUAL A : 31 \\
\end{tabular}} \\
\hline \multicolumn{2}{|c|}{$\begin{array}{l}\text { LOCALIZACION: } \\
\text { Fachada Sur. }\end{array}$} \\
\hline \multicolumn{2}{|c|}{ 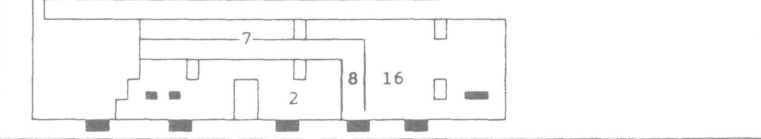 } \\
\hline \multicolumn{2}{|c|}{ MAS INFORMACION EN: 7,31} \\
\hline \multirow{2}{*}{\multicolumn{2}{|c|}{$\begin{array}{l}\text { INTERPRETACION: Ya que traba perfectamente con el EL. ne7 } \\
\text { y posee las mismas caracteristicas, pertenece posiblemente a la } \\
\text { ampliación románica, pero esta vez en longitud. } \\
\text { Es dificil precisar las causas de esta ampliación } \\
\text { románica pero dado que reaprovechan la estructura preexistente } \\
\text { no debe hacerse por problemas de solidez, y tampoco por proble- } \\
\text { mas de espacio pues aumenta muy poco, sino más bien por una } \\
\text { reforma estetica. } \\
\text { El borde desgastado indica una zona de paso, actual } \\
\text { mente desaparecida, por ello, este tramo no tendria una lon- } \\
\text { gitud mayor en origen y seria una esquina. }\end{array}$}} \\
\hline & \\
\hline FECHA PROPUESTA: & $\begin{array}{l}\text { REDACTOR: } S . \text { Feijoo } \\
\text { FECHA: } 17-4-92\end{array}$ \\
\hline
\end{tabular}

Fig.1.- Ejemplo de ficha de elementos utilizada.

Esta proporción tan alta puede deberse a la casualidad, pero vale como indicativo de la magnitud del problema y demuestra que San Martín de Prado no es un caso aislado.

Ahora sí disponemos del instrumento para la lectura de edificios y, desde luego, es conveniente aplicarlo en estos casos de una forma sistemática. Una simple prospección visual por alguien especializado puede determinar las iglesias que conviene estudiar detenidamente; y si esto no es posible, hacerlo siempre antes de cualquier actuación que las pueda afectar.

Este trabajo puede ser un ejemplo de cómo, con un bajo coste, es factible tener documentada y analizada una iglesia, modesta, de tantas como existen en nuestra geografía. Por supuesto estamos de acuerdo con la necesidad de buenas planimetrías, pero nosotros, dado que no contábamos con ningún tipode subvención, debimos suplirla con croquis en las fichas de elementos (Fig. 1) y con esquemas en el texto.

Se situó geográficamente cada una de las iglesias de la comarca mediante el código postal. Se numeraron por orden alfabético ( $\mathrm{n}^{\circ}$ de Edificio) y, a continuación, se añadió el número de Estructura. San Martín de Prado

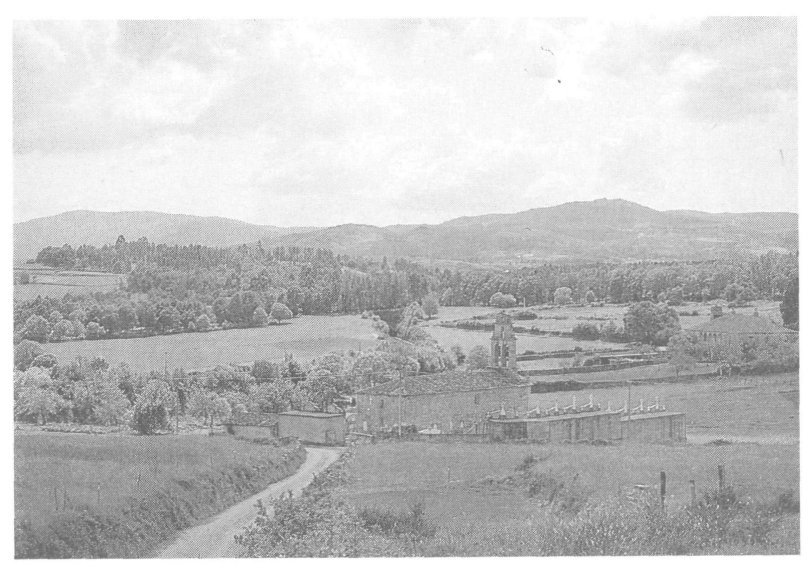

Fig.2.- San 1 Hartin de' P'rado.

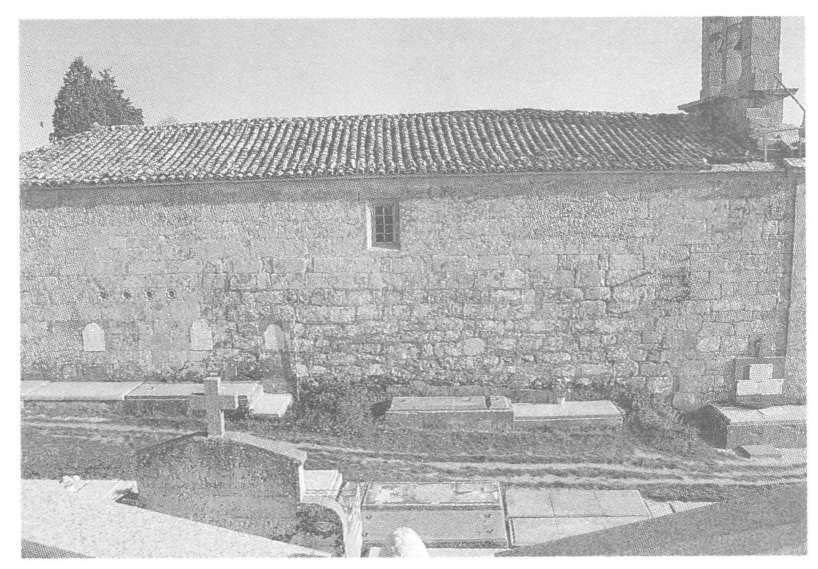

Fig.3.- San Martin de Prado. Fachada Norte.

(Figs. 2 y 3) es la $36512 / 37$ y está compuesta por cuatro estructuras (la última, contemporánea, no la incluimos en el presente artículo por estar sólo compuesta de tumbas adosadas a la iglesia). Los elementos se diferenciaron lo más exhaustivamente posible, señalándolos en los croquis del edificio (Figs. 4 y 5) realizados a mano alzada. No estudiamos las fachadas E. y O. por ser clarísimamente unitarias con la tercera etapa, moderna, de la iglesia. Tampoco estudiamos el interior por haber sido objeto de una de esas "restauraciones" antes aludidas, consistente en aplicar un enlucido de hasta $2 \mathrm{~cm}$ de grosor de cemento azul pintado posteriormente de blanco.

Antes de entrar en el análisis pormenorizado de la iglesia, debemos agradecer al Dr. Luis Caballero Zoreda sus comentarios, que han ayudado a enriquecer la lectura del edificio en varios puntos, y a Fernando Arce Sainz sus aportaciones al texto.

\section{Descripción de la actividad constructiva}

\subsection{1 - Fase prerrómanica}

Sólo se aprecia en las fachadas N. y S. y, aunque sus características generales coinciden (hiladas irregulares de 
forma sinuosa; acabado muy rugoso; abombamiento del muro en dos partes), en ellas hay algunas diferencias particulares que conviene resaltar: La fachada S. está expuesta a los vientos dominantes, por lo que aparece más desgastada en conjunto aquí; el encintado románico (El. $n^{\circ}$ 19) prácticamente ha desaparecido y deja ver la forma de los sillares, que varían de módulo y perfección en la talla:

-En las dos hiladas inferiores (Fig. 6) son más anchos, 41 $\mathrm{cm}$ de media, y con las esquinas bien escuadradas, de tal forma que se utilizan muy pocos ripios en las juntas.

-En las inmediatamente superiores van disminuyendo de anchura, algunos son muy alargados, y las esquinas se van redondeando utilizando más calzos (Fig. 7).
-En la esquina superior derecha, entre la ventana $n^{\circ} 6$ y el E1. $n^{\circ} 8$, vuelven a ser como en el primer caso, con la salvedad de que están alisados en vez de tener una superficie rugosa (Fig. 8).

Este último dato puede apuntar a una segunda fase en la iglesia prerrománica, aunque nosotros pensamos que ha sido retocado al construir el El. $n^{\circ} 8$, ya que en este punto, por el abombamiento que tiene, el muro prerrománico sobresaldría de la vertical, produciéndose un escalonamiento respecto a la ampliación románica que ha sido hecha a plomada. Así, esta discontinuidad habría sido picada y alisada para hacerlos coincidir.

La sillería parece fabricada exprofeso y no reutilizada.

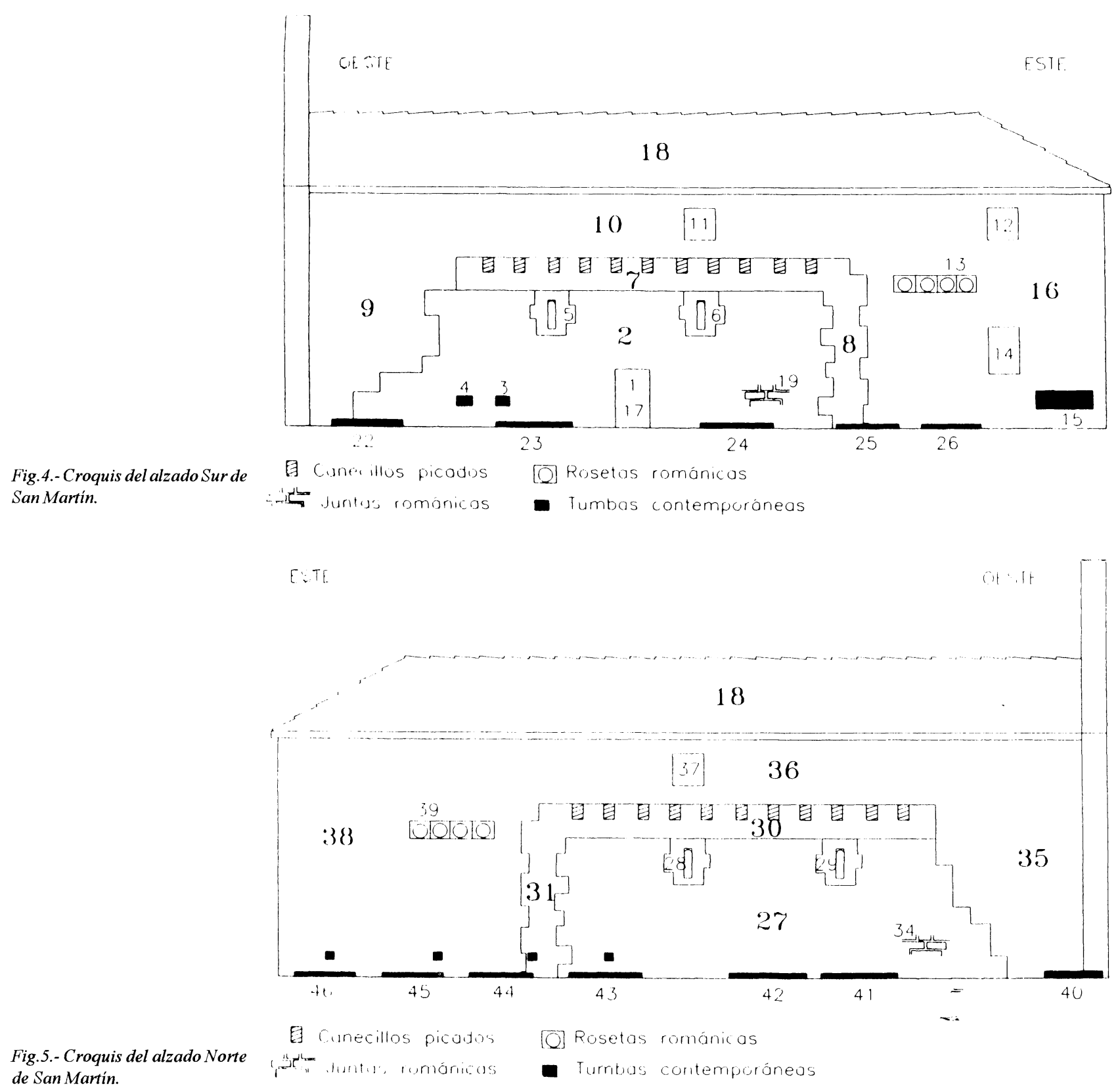




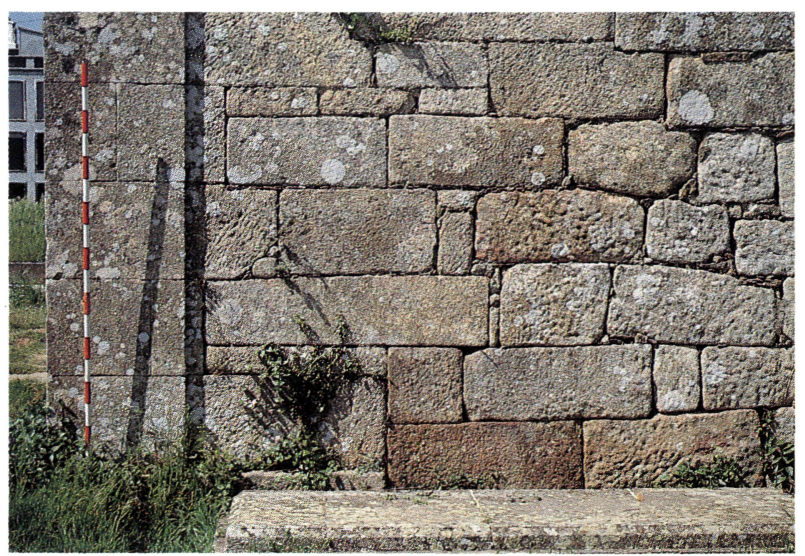

Fig.6.- Fachada Sur. Silleria prerrománica de las hiladas inferiores. Se aprecia la esquina SO de la iglesia prerrománica y cómo rompe y se adosa el muro moderno a ella. Aqui no hay elementos románicos por lo que pensamos que esta fase sólo afectó a la puerta de los pies y no a toda la fachada oeste.

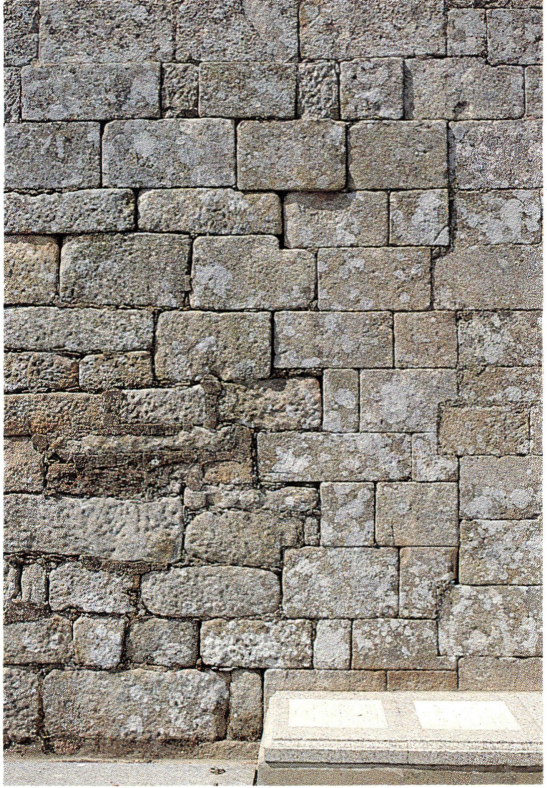

Fig.9.- Paramentos prerrománico/románico/moderno. Se aprecia cómo el tercero rompe y se adosa al segundo y cómo el segundo hace lo mismo con el primero.

Mientras que en las hiladas superiores puede serlo por las esquinas redondeadas, en las inferiores se ve claramente que no $\mathrm{y}$, dado que tienen ambas el mismo acabado $\mathrm{y}$ características, seguramente ninguna lo sea. Además, en la fachada $\mathrm{N}$. todo el paramento es unitario y, en ninguna, aparecen piezas con formas que nos indiquen la reutilización de elementos anteriores.

La planta de la primera iglesia no se puede reconstruir sin excavar arqueológicamente, ya que sólo se ha conservado la esquina SO. que nos indica la situación de la fachada principal (Fig. 6). En las esquinas SE. y NE. puede parecer en un principio que los Els. $n^{\circ} 8$ y 31 (románicos) sólo rompan los sillares a tizón de 2 y 27 (prerrománicos) respectivamente para trabar con ellos, por lo que los sillares que no han sido tocados marcarían estas esquinas de la iglesia prerrománica. Si así fuera, el ancho de los tizones sería muy pequeño, $20 \mathrm{~cm}$, por lo que la reforma románica rompe, por lo menos, el largo de un sillar del muro prerrománico (Fig. 9). Esto resulta curioso al ser constructivamente innecesario y el ejemplo no está a más de un metro: los Els $n^{\circ} 16$ y 38 para trabar con 8 y 31 sólo cortan lo imprescindible para que unan bien. Entonces, ¿qué pasa en la unión de lo románico con lo prerrománico?: posiblemente fuera necesario rehacer estas esquinas, pero esto será explicado en la fase románica.

La datación de la iglesia prerrománica es muy aventurada, aunque se pueden apuntar algunos datos basándonos en el trabajo de Karen Kingsley (1980: 178 y ss.). La sillería no es reutilizada; esto restringe la cronología a dos épocas
Fig.8.- Fachada Sur. Sillares de la esquina superior derecha del paramento prerrománico, posiblemente repicados al hacerse la ampliación en altura románica.

(c) Consejo Superior de Investigaciones Científicas Licencia Creative Commons 3.0 España (by-nc) 


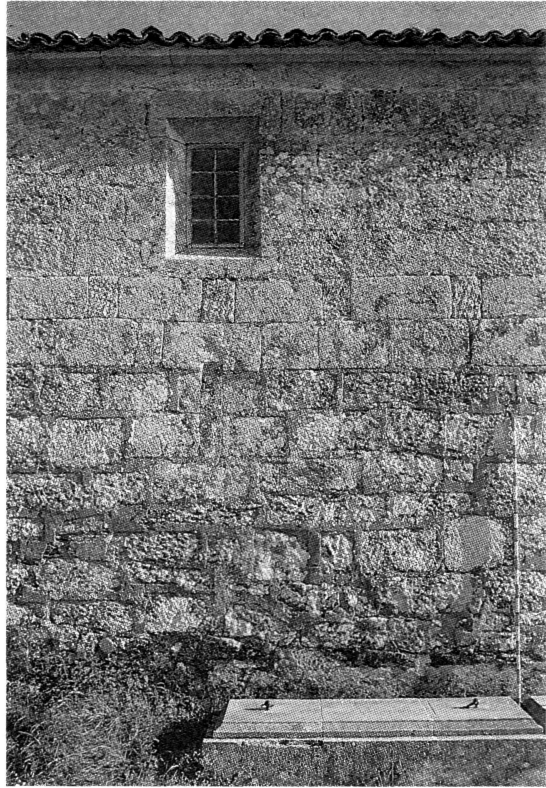

Fig.10.- Ampliación románica en altura (bajo la ventana). Donde los sillares a tizón son los canecillos cortados en la reforma moderna, con la hilada previa de regularización. Bajo estas dos hiladas está el muro prerrománico y sobre ellas el moderno.

posibles, ya que en el lapso entre el s. VIII y el X la reutilización y el pequeño tamaño de los sillares es la norma común. En San Martín de Prado las dimensiones se dividen en tres tipos: $74 \times 41 \mathrm{~cm}, 71 \times 30 \mathrm{~cm}$ y $71 \times 24 \mathrm{~cm}$, como norma general, pues la longitud varía hasta llegar en algún caso hasta los $125 \mathrm{~cm}$, o por el contrario, no llegar a los 40. Estas medidas se pueden encuadrar desde el s. VI al VII o desde el X al XI, siendo imposible actualmente adscribirla fielmente a ninguna de estas fechas. Sólamente señalar que los abombamientos del paramento prerrománico ya existían previamente a la ampliación románica. Esto puede conferirle una mayor antigüedad a la primera iglesia, aunque desde luego, no es determinante.

\subsection{2 - Fase románica}

Como la prerrománica, sólo se conservan restos en alzado en las fachadas norte y sur y las dos siguen el mismo esquema: se realiza una ampliación de dos hiladas en altura y otra de $60 \mathrm{~cm}$ hacia el este, a la vez que se abren dos vanos en cada fachada. Esta reforma de la iglesia prerrománica se hace siguiendo todos los cánones del Románico de la zona, por lo que siguiendo este razonamiento es posible reconstruir hipotéticamente sus características.

La ampliación en altura (Els. $n^{\circ} 7$ y 30$)$ posiblemente sólo se realizara para incluir los canecillos. De esta forma, se superpone una primera hilada que regulariza las ondulaciones de la sillería prerrománica, sobre la cual se colocan los canecillos (Fig. 10), perdidos actualmente al ser picados en la reforma moderna.

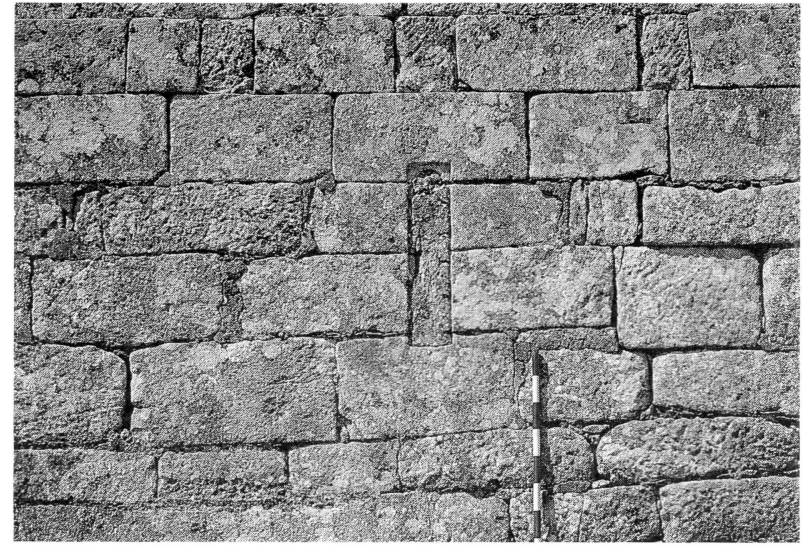

Fig.11.-Fachada Sur.Ventana románica cortando al muro prerrománico

Las ventanas rompen el paramento prerrománico (Fig 11), aunque hemos dudado de si en vez de romper y hacerse las ventanas completas, no han sido talladas en parte en los sillares prerrománicos. Nos hemos decidido por la primera opción por ser la más probable, ya que la segunda sería más difícil de realizar. Las ventanas siguen también el canon de la zona: vano rectangular con un arco de medio punto rehundido.

La ampliación hacia el este (Fig. 12) es tan pequeña, $60 \mathrm{~cm}$, que no tiene sentido como tal. Tomando como punto de partida el problema de por qué rompe más de lo necesario el paramento prerrománico, se pueden enunciar dos hipótesis:

-Que las esquinas prerrománicas tuvieran peligro de arruinarse o que estuvieran ya en ruina y que por ello se reformaran

-Que la reforma incumbiera a toda la cabecera de la iglesia.

Nos inclinamos por la segunda solución, pues la reforma de las esquinas, de arriba a abajo, apunta más a un nuevo ábside que a una consolidación. Además, existen ocho

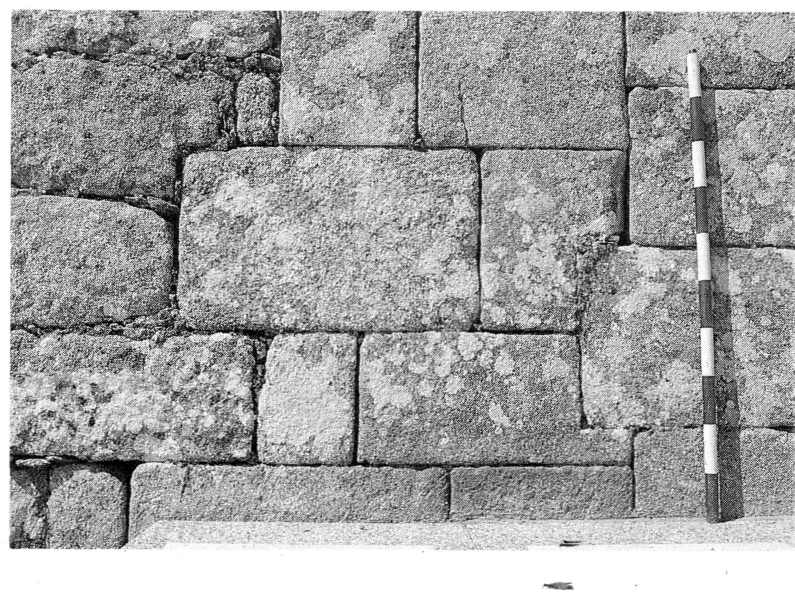

Fig.12.- Fachada Sur. Ampliación hacia el Este. Se aprecian los tres paramentos prerrománico / románico / moderno. 


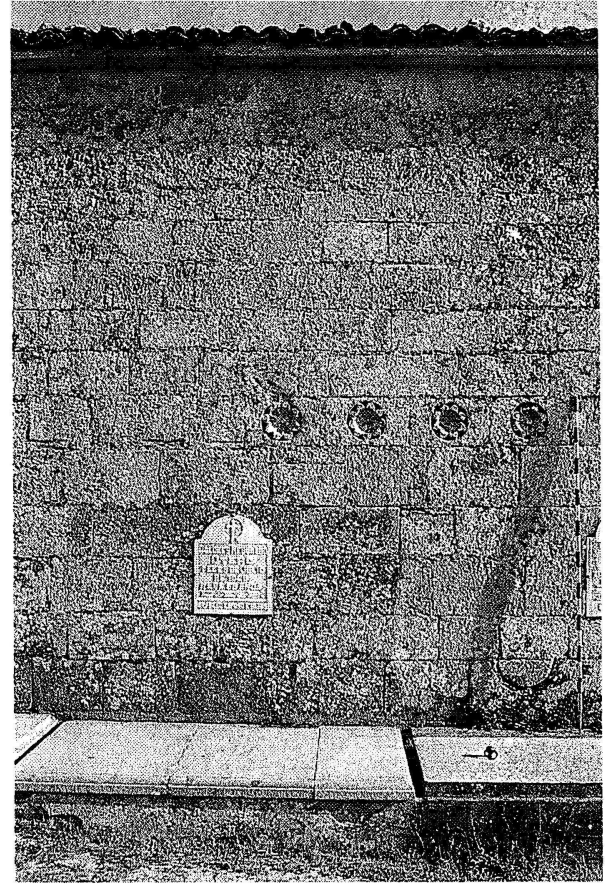

Fig.13.- Posibles metopas románicas reutilizadas enel paramento moderno.

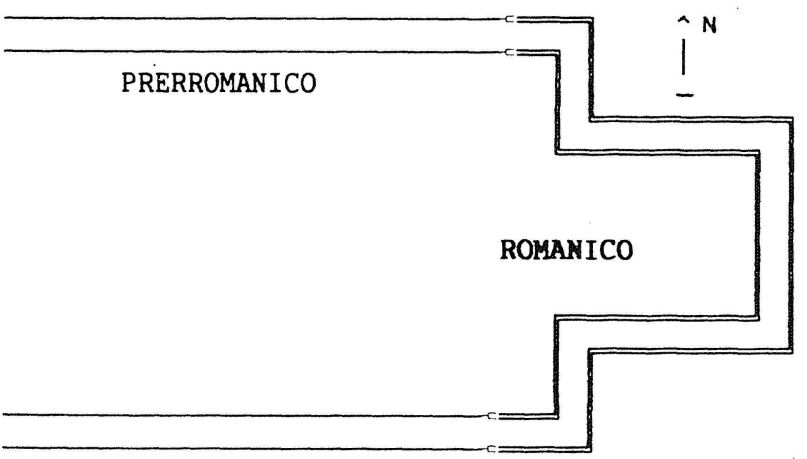

Fig.14.- Posible planta del ábside románico de San Martin de Prado

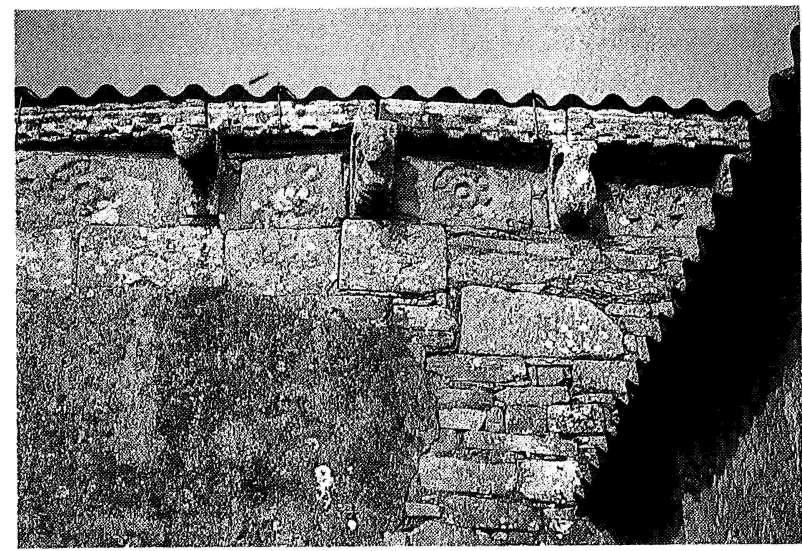

Fig.15.- Canecillos y metopas en Santa María de Bermés. sillares decorados con rosetas de botón central (Fig. 13) reaprovechados en la reforma moderna, y éstos no pueden provenir de otrolugar que de un ábside de factura románica. Aquí no resulta difícil reconstruir la planta de la iglesia románica (Fig. 14), teniendo en cuenta que todas las cercanas tienen el ábside rectangular: San Martín de Lalín, San Julián de Rodís, San Juan de Anzo, Santiago de Taboada, etc.

Los sillares con rosetas, como ya hemos indicado, estarian situados en el ábside y serían posiblemente metopas alternando con los canecillos, como en la vecina iglesia de Santa María de Bermés (Fig. 15). Ésta, con casi total seguridad, también sería prerrománica pues, al igual que San Martín, tiene una ampliación en altura de dos hiladas para añadir los canecillos y las metopas sobre el posible paramento prerrománico. Apoyandoesto hay un documento del 747 donde Santa María de Bermés es donada a la iglesia Lucense (Cañizares, 1946: 100).

El encintado que recubre las juntas prerrománicas(Fig. 16) tiene un dibujo que simula sillares bien escuadrados. Nosotros lo adscribimos al románico, ya que no aparece en ningún paramento moderno (éstos tienen en algunas partes otro completamente diferente), mientras que ligeramente sí cubre algunos sillares románicos. Se conserva casi integro en la fachada N. y muy fragmentado en la S. Su función es la de regularizar la sillería prerrománica para que coincida con el gusto estético del Románico, aunque tampoco se descarta que fuera también para consolidar el edificio y evitar humedades, ya que la argamasa del paramento prerrománico prácticamente ha desaparecido (actualmente hay más de cinco nidos de pájaros en el interior del muro). Esto viene avalado porque no se limitan a encintar, sino que también introducen gran cantidad de ripios, en su mayoría tejas, para calzar los sillares.

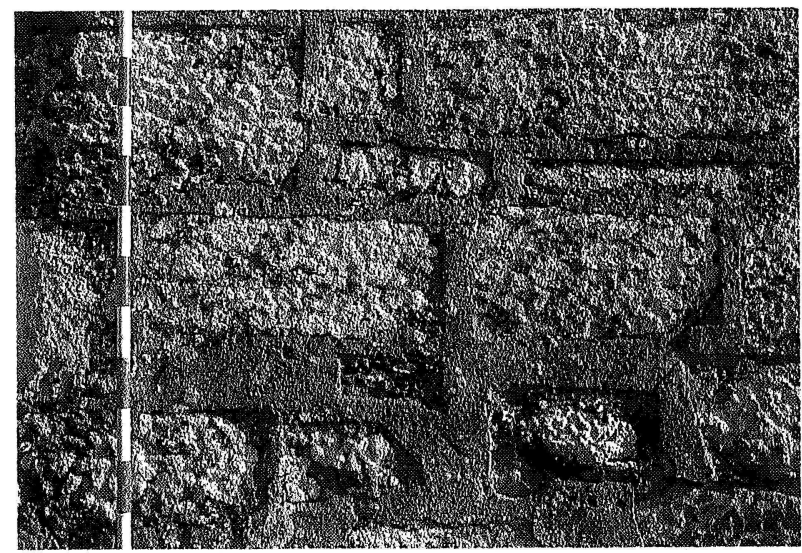

Fig.16.- Encintado románico sobre las juntas prerrománicas simulando sillares escuadrados. 
De la fachada románica no se conserva nada -si hubiera sido reformada como las esquinas SE. y NE. quedaría algún resto, y en la esquina SO. prerrománica no hay huellas de ello-. Por lo cual, creemos que sólo afectó a la puerta. Esto es seguro porque en el vecino Pazo de Liñares se conservan cinco dovelas decoradas con ajedrezado, reutilizadas en una columna, y una pintura en la pared de la entrada que posiblemente corresponda a la fachada de la iglesia antes de la reforma moderna. También aquí hay dos capiteles románicos con motivos vegetales reutilizados en los pies de un hórreo.

La mayoría de las iglesias de la comarca poseen una entrada secundaria que normalmente se suele situar en el S. San Martín de Prado la tiene pero es de factura moderna, aunque es posible que reforme otra anterior.

Hay un elemento de la iglesia al que no hemos encontrado explicación: una piedra informe que sobresale ligeramente de la primera hilada del El. $\mathrm{n}^{\circ} 7$, entre las ventanas, y que pasaría como una simple irregularidad si no la hubiésemos visto también en la iglesia de San Julián de Pedroso, a 18 $\mathrm{km}$ de Prado, exactamente en la misma situación y de igual forma. La iglesia de Pedroso es completamente románica y de muy buena factura toda ella, siendo prácticamente posible igual a como sería San Martín de Prado románico, con, seguramente, la misma planta y casi las mismas dimensiones. En ella esta piedra es claramente intencionada $\mathrm{y}$, por tanto, en la de Prado también, pero a nosotros se nos escapa su función.

En general, en la fase románica de San Martín de Prado hay un cambio claro en la sillería que ahora es más pequeña pero más regular en su forma: están bien escuadrados y con un acabado liso (Fig. 17).

Para esta iglesia se puede especificar más la cronología: ya en el 1167 figura en una donación de Guntina Núñez a su

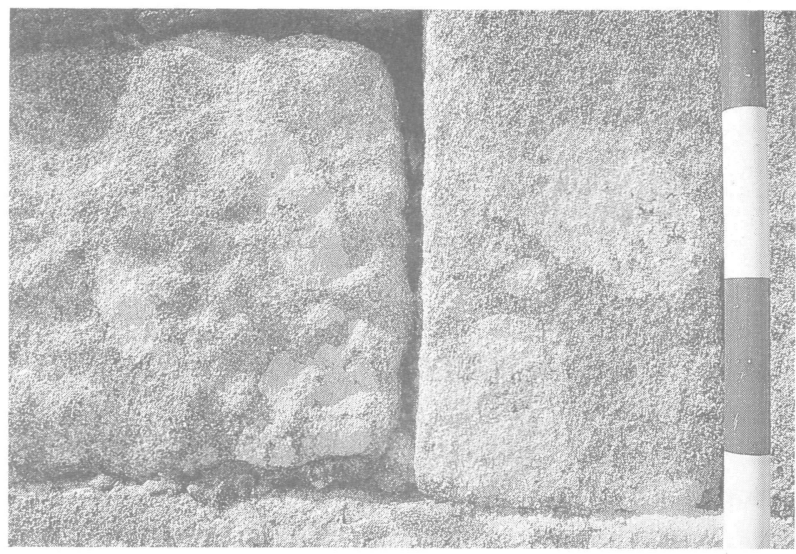

Fig.17.- Diferencia de talla entre lo prerrománico y lo románico. hijo Fernán Pérez, monje de Carboeiro (González, 1989: 234 y Bango Torviso, 1979) y por paralelos no se retrasaría más allá de mediados del s.XII

\subsection{3- Fase moderna}

Esta etapa se caracteriza por una reforma integral de la iglesia. Se amplía en altura, se rehace la fachada con su espadaña y todo el ábside, incluyendo una pequeña sacristía tras él, que exteriormente no está diferenciada.

En apariencia es uniforme, pero contiene muchas irregularidades: en las ampliaciones al $\mathrm{O}$. se aprecia un cambio en la sillería, que pasa de ser perfecta en las esquinas a ser muy irregular al adosarse a lo románico y prerrománico. Lo mismo pasa en la ampliación en altura: las primeras hiladas son más uniformes, mientras que, conforme se acerca al tejado pierden calidad, por lo que se mimetizan con un revoco parcial. En todo el paramento se reutiliza material anterior, no sólo las rosetas románicas sinotambién muchos sillares, incluso prerrománicos, restos de molduras, fustes de columna, etc

No se aprecian diferencias cronológicas en estas ampliaciones, pero sí etapas de obra. Se comenzaría construyendo primero la fachada principal y la elevación en altura para terminar con la sacristía. Esto se ve muy bien en la fachada $\mathrm{N}$. donde 38 se adosa en parte a 36 , por lo que es posterior como etapa, pero contemporáneo a todos los efectos, ya que traban en la última hilada. Esta zona es interesante constructivamente por la solución que toman (Figs. 18 y 3 )

Seguramente la última hilada, bajo el tejado, se hace completa de comienzo a fin pasando por 35,36 y 38 , ya que es uniforme y así cose toda la estructura.

La fecha de construcción para esta fase debe aparecer en

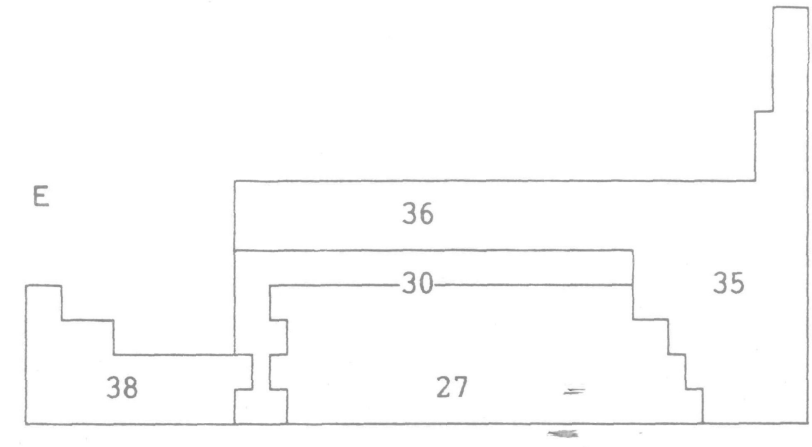

Fig.18.- Al construir 36 y no estar hecho todavía 38 deben acabarlo en esquina para asegurarlo, para luego ya, trabarlos. 
Fig.19.- Diagrama estratigráfico de la fachada Sur de San Martin de Prado.
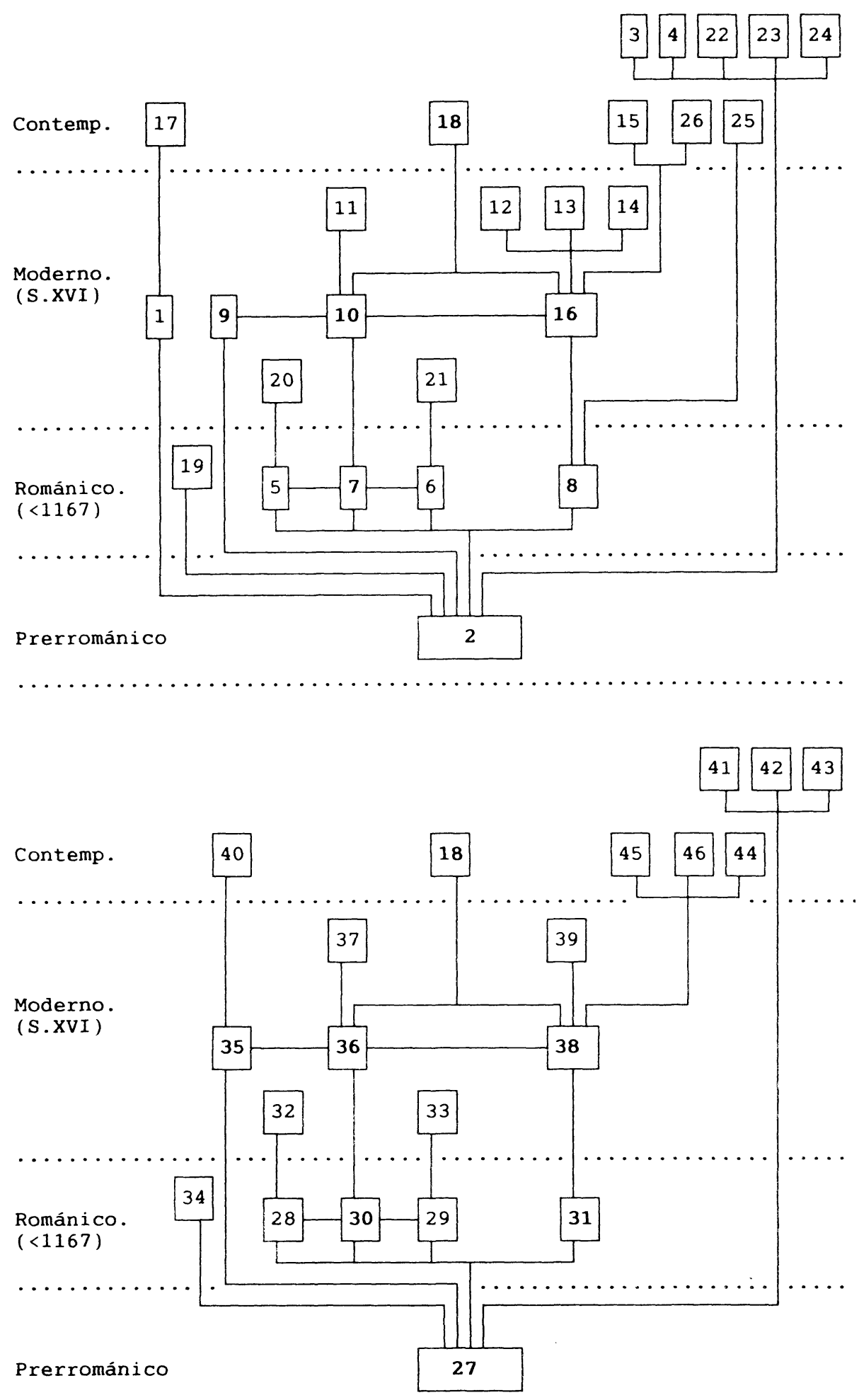

Fig.20.- Diagrama estratigráfico de la fachada Norte de San Martín de Prado. documentos y, a la espera de poder consultarlos, nos basamos en la ambigua descripción que hace González (1989: 234), que la denomina de "estilo renacentista", por lo que sería del s.XVI. De todas formas es muy posible que sea mucho más moderna, incluso nos aventuramos a decir que es del siglo pasado por varias razones: no tiene ningún tipo de desgaste, estando prácticamente tal y como se hizo; por la existencia de la tumba 15 , que aparece integrada en el paramento sin huellas de ruptura, donde la fecha de defunción más antigua es de 1834. Esta tumba pertenece a los antiguos señores del lugar que serían, posiblemente, los que costearan las obras. Por esto proponemos que la remodelación está hecha a comienzos del s.XIX, aunque mantenemos la cronología del s.XVI. 
Unidades prerrománicas.

\begin{tabular}{|c|l|c|c|}
\hline UED & FACHADA & DESCRI PCION & ANTERIOR \\
\hline 2 & sur & Paramento prerrománico & $1,3,4,5,6,7,8,9,19,22,23,24$ \\
\hline 27 & norte & Paramento prerrománico & $28,29,30,31,34,35,41,42,43$ \\
\hline
\end{tabular}

Unidades románicas.

\begin{tabular}{|c|l|l|l|l|}
\hline UEM & FACHADA & \multicolumn{1}{|c|}{ DESCRIPCION } & \multicolumn{1}{|c|}{ ANTERIOR } & \multicolumn{1}{|c|}{ POSTERIOR } \\
\hline 5 & sur & ventana izquierda & 19,20 & 2,7 \\
\hline 6 & sur & ventana derecha & 21 & 2,7 \\
\hline 7 & sur & ampliación en altura & $5,6,9,10,16$ & 2,8 \\
\hline 8 & sur & ampliación al este & 16,25 & 2 \\
\hline 19 & sur & juntas y encintado & & 2,7 \\
\hline 28 & norte & ventana izquierda & 32,34 & 27,30 \\
\hline 29 & norte & ventana derecha & 33,34 & 27,30 \\
\hline 30 & norte & ampliación en altura & $35,36,38$ & 27 \\
\hline 31 & norte & ampliación al este & $38,43,44$ & 27 \\
\hline 34 & norte & juntas y encintado & & $27,30,31$ \\
\hline
\end{tabular}

Unidades modernas.

\begin{tabular}{|c|c|l|l|l|}
\hline UEM & FACHADA & \multicolumn{1}{|c|}{ DESCRIPCION } & ANTERIOR & \multicolumn{1}{|c|}{ POSTERIOR } \\
\hline 1 & sur & Puerta & 17 & 2 \\
\hline 9 & sur & Ampliación a oeste & 18,22 & 2 \\
\hline 10 & sur & Ampliación en altura & 18 & 7 \\
\hline 11 & sur & Ventana dentro de 10 & & \\
\hline 12 & sur & Ventana superior dentro de 16 & & \\
\hline 13 & sur & Rosetas románicas reutilizadas & & \\
\hline 14 & sur & Ventana inferior dentro de 16 & & \\
\hline 16 & sur & Ampliación, ábside y sacristía & $15 ?, 18,26$ & 7,8 \\
\hline 20 & sur & Relleno que ciega la ventana 5 & & 2,5 \\
\hline 21 & sur & Relleno que ciega la ventana 6 & & 6,7 \\
\hline 32 & norte & Relleno que ciega la ventana 28 & & 28,30 \\
\hline 33 & norte & Relleno que ciega la ventana 29 & & 29,30 \\
\hline 35 & norte & Ampliación, fachada principal & 18,40 & $27,30,39$ \\
\hline 36 & norte & Ampliación en altura & 18,38 & 30 \\
\hline 37 & norte & Ventana dentro de 36 & & \\
\hline 38 & norte & Ampliación, ábside y sacristía & $18,44,45,46$ & 31,36 \\
\hline 39 & norte & Rosetas románicas reutilizadas & & \\
\hline & & & & \\
\hline
\end{tabular}

Fig.21.- Listado de elementos.

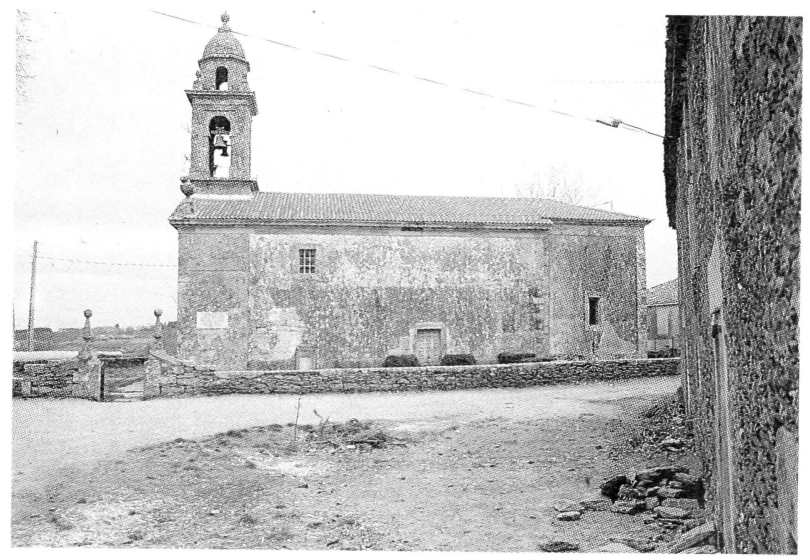

Fig.22.- San Estebo de Barcia.

(c) Consejo Superior de Investigaciones Científicas

\section{Conclusiones}

La iglesia de San Martín de Prado creemos que es la punta de un iceberg, pues pensamos que muchas de las parroquias rurales en Galicia han tenido un uso continuado desde la Alta Edad Media hasta nuestros días. Esto aparece claramente en San Martín con una secuencia cronológica, definida mediante la Lectura Estratigráfica Muraria (Figs. 19 y 20), donde se aprecia perfectamente la pervivencia del uso desde la primera estructura hasta la última. Esta secuencia se ve representada en los croquis del edificio y desglosada en las fichas de elementos (a disposición de cualquier interesado/a) o, en su defecto, en el listado de elementos adjunto (Fig. 21).

Las conclusiones sobre San Martín, como hemos dicho anteriormente, se pueden enriquecer notablemente si se analizara junto con otras iglesias similares del entorno. Aun así, aparte del dato del descubrimiento de una nueva iglesia prerrománica, el tipo de talla y de paramento de ésta es lo suficientemente especial como para configurar por sí mismo una tipología, aunque, hoy por hoy, no seamos capaces de datarlo más concretamente. Este paramento, igual, aparece con un desconchón en el enlucido de la iglesia de San Estebo de Barcia (Figs. 22 y 23), a cinco kilómetros de Prado; por lo cual, es posible que ésta también sea prerrománica a su vez.

Hay que destacar el carácter de la reforma románica, pues prácticamente consiste en una operación de maquillaje de la iglesia anterior. El objetivo es adecuar la estructura preexistente a la corriente artística entonces vigente, para lo cual se añaden los elementos básicos que la definen: los canecillos, posiblemente la portada de los pies, las ventanas, el ábside, y, sin olvidar la apariencia de la sillería prerrománica, el encintado (dato a nuestro parecer muy relevante, pues se constata que la sillería es un elemento definitorio de un estilo artístico y, por tanto, de un período histórico)

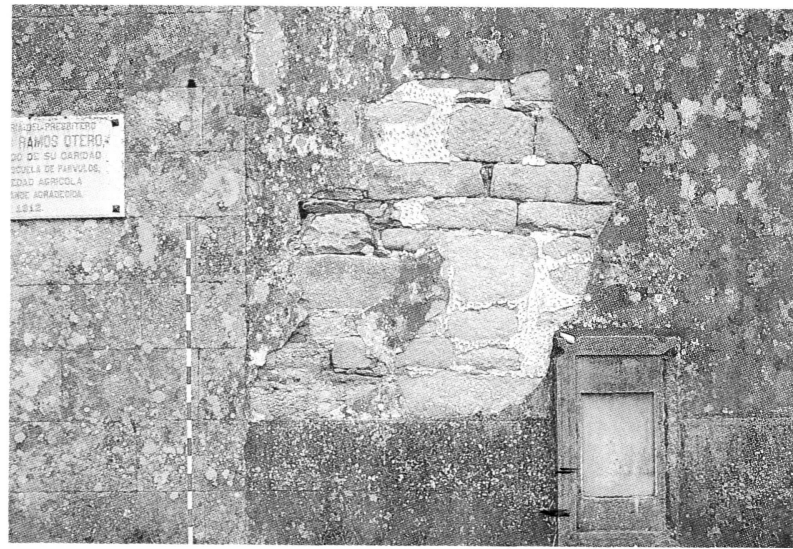

Fig.23.- Posible paramento prerrománico en San Estebo de Barcia. 
Otro dato interesante es la situación de San Martín respecto al pueblo. Prado esta compuesto por un núcleo de algo más de cien habitantes y una serie de aldeas diseminadas por los $144,6 \mathrm{~km}^{2}$ que posee la pedanía y, curiosamente, la iglesia está entre campos de cultivo y prados de pasto, a trescientos metros del pueblo y cien de la casa más cercana. Nos planteamos si siempre había sido así, y no encontramos ningún indicio de un posible asentamiento junto a ella.
Esto puede apuntar a que primitivamente hubiese sido una ermita, o a que los parámetros de asentamiento de Prado se hayan mantenido constantes hasta nuestros días. En principio, nos decantamos por la segunda hipótesis, pues no hay datos que avalen la primera, y sí, en cambio, la mera presencia de esta estructura de asentamiento puede ser debida a que continúe con un esquema igual anterior a ella.

\section{BIBLIOGRAFÍA}

BANGO TORVISO, I. Arquitectura románica en Pontevedra. Fundación Pedro Barrie de la Maza (1979).

BROGIOLO, G. P., Architectture medievali del Gardabresciano, analisi stratigrafiche. Grafo.

BROGIOLO, G.P., Castello di s. Martino (Cervarese S. Croce -Pd). Analisistratigrafica delle murature, Dattiloscritto( 1987).

BROGIOLO, G.P., Archeologia dell 'edilizia storica, Edicioni New Press-Como (1988).

CABALLERO ZOREDA, L., El método arqueológico para la comprensión de un edificio. Dualidad, sustrato arqueológicoestructura.Curso de mecánica y tecnología de los edificios antiguos. COAM (1987). Pag. 13-59.

CAÑIZARES REY, B., El monasterio de San Martín de Lalín. Museo de Pontevedra (1942).

CAÑIZARES REY, B., Onomástica de lugares de Deza mencionados antes del s.XV. Museo de Pontevedra (1946).

CRAIG SPENCE (ED.), Archaeological site manual. The Museum of London, 2- Ed. (1990).

DE SÁ BRAVO, H., Rutas del románico en la provincia de Pontevedra. Caja Rural Provincial de Pontevedra. (1978).
GARCÍA ALÉN, A.Y FILGUEIRA VALVERDE, J., Carta arqueológica de la provincia de Pontevedra. Adiciones a la misma... "Museo de Pontevedra", (1953 y 1959).

GONZÁLEZ ALÉN, D. Y VÁZQUEZ CRESPO, A., A comarca do Deza. Diputación de Pontevedra (1989).

FATÁS, G. Y BORRÁS, G.M., Diccionario de términos de arte y elementos de arqueologia, heráldica y numismática. Alianza Editorial. 5- Ed. (1990).

HARRIS, E.C., Principles of Archaeological Stratigraphy. Londres (1979).

HARRIS, E.C., Principios de Estratigrafia Arqueológica, Ed. Crítica, Barcelona (1991).

KINGSLEY, KAREN, Visigothic Architecture in Spain and Portugal: Astudy in masonry, documents, and form. Berkeley (1980).

NÚÑEZ RODRÍGUEZ, M., Arquitectura prerrománica. COAG (1978).

PARENTI, R., La lettura stratigrafica delle murature in contest $i$ archeologici e di restauro. Cittá e Restauro, I. n-2 pp 55-68. (1985). 